\title{
Terrários no ensino de ecossistemas terrestres e teoria ecológica
}

\author{
Terrariums in teaching the terrestrial ecosystems \\ and ecological theory
}

Rosane Teresinha Nascimento da Rosa

\begin{abstract}
Resumo
Os terrários são apontados, em muitas sugestões bibliográficas, para serem utilizados como "modelos de Ecossistemas terrestres". Este artigo relata a experiência realizada com estudantes de sexta série do ensino fundamental por suas professoras de Ciências, no qual foram construídos Terrários e estes foram observados durante trinta dias. O estudo permitiu detectar os princípios da Teoria Ecológica que não são contemplados na montagem dos mesmos. Concluiu-se que o Terrário não consegue reproduzir as condições do meio ambiente e não se constitui como a metodologia mais adequada para a observação de Ecossistemas terrestres.
\end{abstract}

Palavras-chave: Terrários, Teoria Ecológica, Ensino de Ciências.

\section{Abstract}

The terrariums are pointed in many bibliographical suggestions to be used as 'models of terrestrial Ecosystems'. This article tells the experience carried through with students of the sixth grade of the elementary school as well as the Science teachers who built Terrariums and observed them thirty days. The study allowed to detect the principles of the Ecological Theory that are not observed in their making. It was concluded that the Terrariums cannot reproduce the conditions of the environment and they are not the most appropriate methodology for the observation of terrestrial Ecosystems.

Keywords: Terrariums, Ecological Theory, Teaching of Sciences. 


\section{Introdução}

Os Terrários são apresentados como modelos de Ecossistemas terrestres e constituem-se de mini-laboratórios práticos, através dos quais procura-se reproduzir as condições do meio ambiente. São montados em potes (caixas de vidro tipo aquário), onde são depositados cascalhos, areia, terra preta, pequenas plantas e animais (ex: tatuzinho do jardim, insetos, minhocas e caracóis), assim como um pequeno recipiente com água.

A partir de uma experiência realizada com alunos da sexta série do ensino fundamental, aplicado por professoras de Ciências da rede municipal de ensino de Santa Maria - RS, utilizou-se o recurso da construção de Terrários como forma de observação do meio ambiente e aprimoramento de conhecimentos relacionados à Zoologia e à Ecologia.

Partindo-se do referencial teórico disponível e do planejamento didático das aulas, a experiência com Terrários foi executada e sua análise é apresentada neste artigo.

\section{Fundamentação teórica}

A experiência aqui apresentada é o resultado de uma pesquisa realizada durante o Mestrado em Educação na Universidade Federal de Santa Maria (UFSM), dentro de uma das atividades do Projeto de Atualização e Aperfeiçoamento para a Ação Pedagógica (APAP), denominada Grupos de Trabalho (GT) em parceria com a Secretaria de Educação do Município de Santa Maria (SMEd)/RS, juntamente com um grupo de professores da UFSM (Universidade Federal de Santa Maria/RS), cujo objetivo era o de atualizar os professores de Ciências da rede municipal em atividades de formação continuada.

A experiência consta da montagem de Terrários que simulam um Ecossistema terrestre. Estes são montados em potes (caixas de vidro tipo aquário), nos quais, no fundo, são depositados cascalhos, areia, terra preta, pequenas plantas e animais (ex: tatuzinho do jardim, insetos, minhocas e caracóis), assim como um pequeno recipiente com água. Recomenda-se sua cobertura com um plástico transparente.

Os Terrários foram montados no Grupo de Trabalho (GT) da 6ạ série, envolvendo 5 (cinco) professoras de Ciências da Rede Municipal de diferentes escolas. Estas elaboraram planejamentos didáticos com suporte da bibliografia disponibilizada pelo projeto, com a intenção de montar os Terrários e explorar junto aos seus alunos conhecimentos específicos relacionados à Zoologia e à Ecologia. Na experiência foram utilizados cinco (5) aquários de vidro nas dimensões de $40 \mathrm{~cm} \times 30$ $\mathrm{cm} \times 30 \mathrm{~cm}$. 
Três (3) das professoras que participaram do projeto trabalhavam em escolas da periferia e duas (2) em escolas da zona rural de Santa Maria (RS). As mesmas foram identificadas pelas letras: A, B, C, D e E. A professora A possuía Licenciatura Plena em Ciências Biológicas e Especialização em Zoologia e as demais (B, C, D e E) Licenciatura Curta em Ciências.

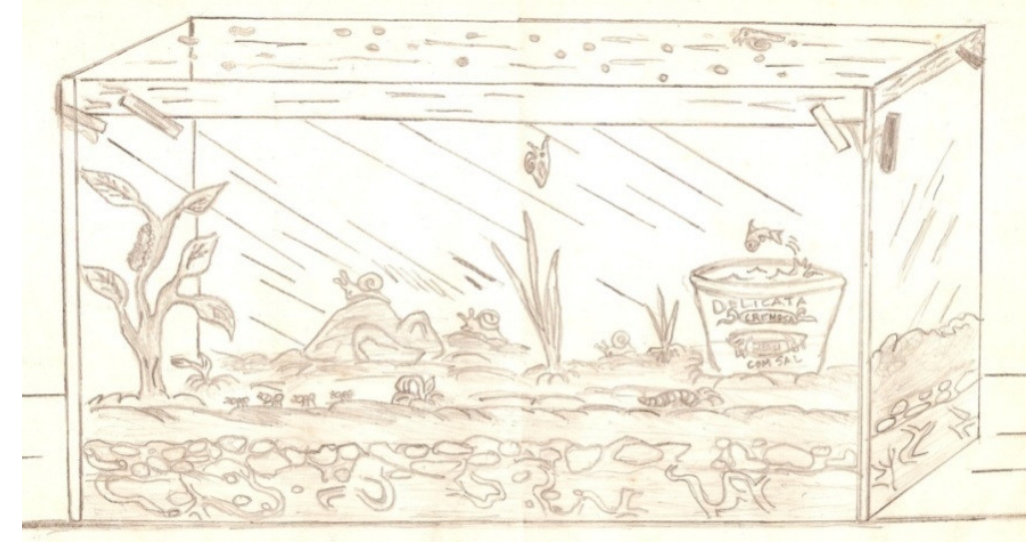

Figura 1- Desenho do Terrário elaborado pelo aluno da professora A

Realizaram-se dez (10) encontros com o grupo de professoras, no ano de 1994, por ocasião da montagem e execução dos planejamentos didáticos. A apresentação dos resultados foi realizada no final de 1994, quando estavam presentes os professores participantes do projeto, a pesquisadora, coordenadoras da disciplina de Ciências da Secretaria Municipal de Educação e professores da UFSM. Os objetivos da experiência de montagem dos Terrários com os alunos foram os seguintes:

- demonstrar um Ecossistema;

- identificar as relações entre os seres vivos;

- identificar os processos metabólicos, como fotossíntese e respiração;

- identificar produtores e consumidores;

- verificar o comportamento, alimentação e reprodução dos animais presentes no Terrário.

O grupo da 6a série optou por 30 dias para observações e conclusões a respeito do uso didático do Terrário. Após a apresentação das professoras do GT 6ạ série, chegou-se à conclusão que era necessário organizar a estrutura desse conhecimento e posteriormente repassá-lo às mesmas, utilizando-se mapas conceituais para representar a estrutura conceitual da Teoria Ecológica e elaborando-se um mapa que contemplasse os conceitos envolvidos no Ecossistema.

Ao término da elaboração do mapa da Teoria dos Ecossistemas, o mesmo serviu de recurso para a análise da teoria presente na bibliografia, que foi utilizada pelo grupo da 6a série 
para elaborar seus planejamentos. O mapa também foi utilizado para a análise dos objetivos presentes nos planos que envolviam os conceitos ecológicos.

Em seguida, fez-se uma comparação dos objetivos presentes nos planejamentos das professoras que enfatizavam a utilização do mesmo como modelo de Ecossistema terrestre e procurou-se relacioná-los aos conceitos da Teoria dos Ecossistemas.

Assim sendo, optou-se em estabelecer um confronto entre os conceitos da Teoria dos Ecossistemas e os objetivos traçados nos planejamentos das professoras do GT 6 a série, utilizando tópicos importantes dessa teoria inspirados em Odum (1988):

a. Princípios e conceitos referentes à Energia dos Sistemas Ecológicos - representados pelos níveis tróficos nas cadeias alimentares;

b. Os ciclos biogeoquímicos - que são os ciclos da matéria. Ex: ciclo do oxigênio, água, gás carbônico e nitrogênio;

c. Dinâmica de populações - os fatores bióticos representados pelas populações de seres vivos devem ficar estáveis, tanto na sua composição quanto no seu tamanho. Esse equilíbrio não é estático, é dinâmico; alguns indivíduos da população morrem ao longo do tempo enquanto outros nascem. Alguns desses atributos são: densidade populacional, taxa de mortalidade e natalidade, taxa de imigração, emigração e taxa de crescimento;

d. Relações e/ou interações populacionais - constituem um dos aspectos mais puramente biológicos da Ecologia, que é a relação entre os organismos. Os organismos não vivem sozinhos, pois estão associados, entre si, pelas comunidades bióticas. Cita-se como exemplo: predação, parasitismo, competição interespecífica e intraespecífica, mutualismo, protocooperação e colonialismo. Veja a comparação na Tabela 1.

\begin{tabular}{|l|l|}
\hline $\begin{array}{l}\text { Objetivos presentes nos planos de aula das } \\
\text { professoras do GT 6a série }\end{array}$ & $\begin{array}{l}\text { Teoria dos Ecossistemas (conceitos e/ou } \\
\text { princípios da teoria baseado em Odum (1988) }\end{array}$ \\
\hline $\begin{array}{l}\text { 1. Reconhecer a relação de alimentação através } \\
\text { da cadeia alimentar }\end{array}$ & $\begin{array}{l}\text { a. Princípios e conceitos referentes à Energia } \\
\text { nos Sistemas Ecológicos }\end{array}$ \\
\hline 2. Reconhecer o ciclo da água & b. Ciclos biogeoquímicos \\
\hline
\end{tabular}




\begin{tabular}{|l|l|}
\hline $\begin{array}{l}\text { 3.a. Descrever a reprodução dos seres vivos na } \\
\text { montagem do Terrário }\end{array}$ & c. Dinâmica de população \\
3.b.Observar a sobrevivência dos seres vivos & \\
\hline $\begin{array}{l}\text { 4 .Identificar as relações entre os seres vivos } \\
\text { presentes no Terrário }\end{array}$ & d. Associações e/ou interações populacionais \\
\hline
\end{tabular}

Tabela 1 - Comparação dos objetivos escritos nos planos de aula das professoras do grupo denominado GT $6 \underline{a}$ série (1, 2, 3 e 4) para utilização do Terrário com os princípios básicos ( $a, b$, c e d) da Teoria dos Ecossistemas baseado em Odum (1988).

\section{Referencial teórico}

De acordo com a bibliografia consultada para elaborar os planejamentos didáticos das professoras do GT 6ạ série (Armando \& Araújo, 1989; Araújo, 1989; Bueno, 1989, Maldaner e Araújo, 1989; Santana, 1992, 1993; Espaço Ciência Viva 1994; Costa e Nascimento, 1994; Colonese, 1994; Delizoicov e Angottl, 1994) o Terrário é visto como um instrumento para tornar o ensino de Ciências mais criativo, dinâmico, possibilitando aos alunos, através de observações sistemáticas, construírem seu conhecimento, atividade em que o professor é um orientador desta tarefa, sendo sugerido para o ensino fundamental, mais especificadamente da 3 a a 6 a séries. Há ênfase na aprendizagem por observação, privilegiando uma concepção empirista da Ciência.

A bibliografia consultada aponta, também, um modelo consagrado para a montagem do Terrário, que envolve os seguintes itens:

- um período determinado de observação, que vai de um ano a uma semana;

- o tipo de recipiente na montagem do Terrário (caixas de vidro de dimensões variadas: aquários, garrafões, pequenos potes, tampinhas de refrigerantes ou garrafões);

- o uso de plástico transparente ou tampa de vidro para vedar o Terrário, sendo que apenas um autor aconselhou a vedação opcional (Armando e Araújo, 1989);

- a origem do material coletado para ser colocado posteriormente no Terrário era sugerida: da casa dos alunos e do pátio da escola (Costa e Nascimento, 1994), do mato e jardins (Espaço Ciência Viva, 1994), de terrenos baldios (Santana, 1992) ou outros não especificados.

As orientações de montagem e exploração do Terrário sugerem seguir as etapas do método científico que são: observação (o que vai acontecer com o Terrário no decorrer do 
tempo?), formulação de hipóteses (os animais vão morrer? o que vai acontecer?), coleta de dados (através do uso de tabelas) e conclusões.

A teoria que dá sustentação a construção de um Terrário é a Teoria dos Ecossistemas ou Ecológica, com seus princípios relacionados a um ciclo de energia, representado, principalmente, pela cadeia alimentar e um ciclo de matéria, através dos ciclos biogeoquímicos (ODUM, 1988).

Partiu-se do princípio de que o conceito de Ecossistema envolve uma totalidade e os conceitos não se encontram isolados, mas relacionados em sistemas de significados que apresentam, freqüentemente, uma estrutura hierárquica de conceitos subordinados (AUSUBEL, 1963; BRUNER, 1963; GAGNÉ, 1970; LAWSON, 1958; NOVAK et al., 1983; PREECE, 1978; SUPPES, 1968; OKEBUKOLA \& JEGEDE, 1988 apud LAWSON, 1994), isto é, estes sistemas de conceitos inter-relacionados são denominados sistemas conceituais.

Como propõe Lawson (1994), um exemplo de sistema conceitual é a Teoria Ecológica. Este sistema está formado de conceitos estruturados segundo uma certa hierarquia. O conceito de Ecossistema inclui a totalidade, portanto estará localizado na sua parte mais alta, pois forma o sistema conceitual conhecido como Teoria dos Ecossistemas. Todos os demais conceitos, começando pelo ciclo de energia e matéria, estão integrados abaixo do conceito de Ecossistema.

Assim os conceitos de ciclos biogeoquímicos, cadeia alimentar com suas unidades básicas (produtores, consumidores, na parte baixa do mapa), estão inter-relacionados e subordinados ao conceito abrangente de Ecossistema. A base do Ecossistema está ancorada nas inter- relações que se estabelecem entre vegetais e animais (interação dos componentes autotróficos e heterotróficos respectivamente) e na superposição de dois ciclos importantíssimos: um de matéria e outro de energia. Tem-se um ciclo aberto de energia que vai regular um ciclo fechado de matéria.

Os componentes e processos que tornam os Ecossistemas funcionais, responsáveis pela sua interação, são: a comunidade biótica, o fluxo de energia (o sol) e a ciclagem de materias (ciclos biogeoquímicos). Abaixo, elaborou-se um mapa representativo da estrutura conceitual dos Ecossistemas, ou seja, a representação esquemática e concomitante dos diversos elementos que o constituem e as suas inter-relações de conceito para a melhor explicitação da Teoria Ecológica. 


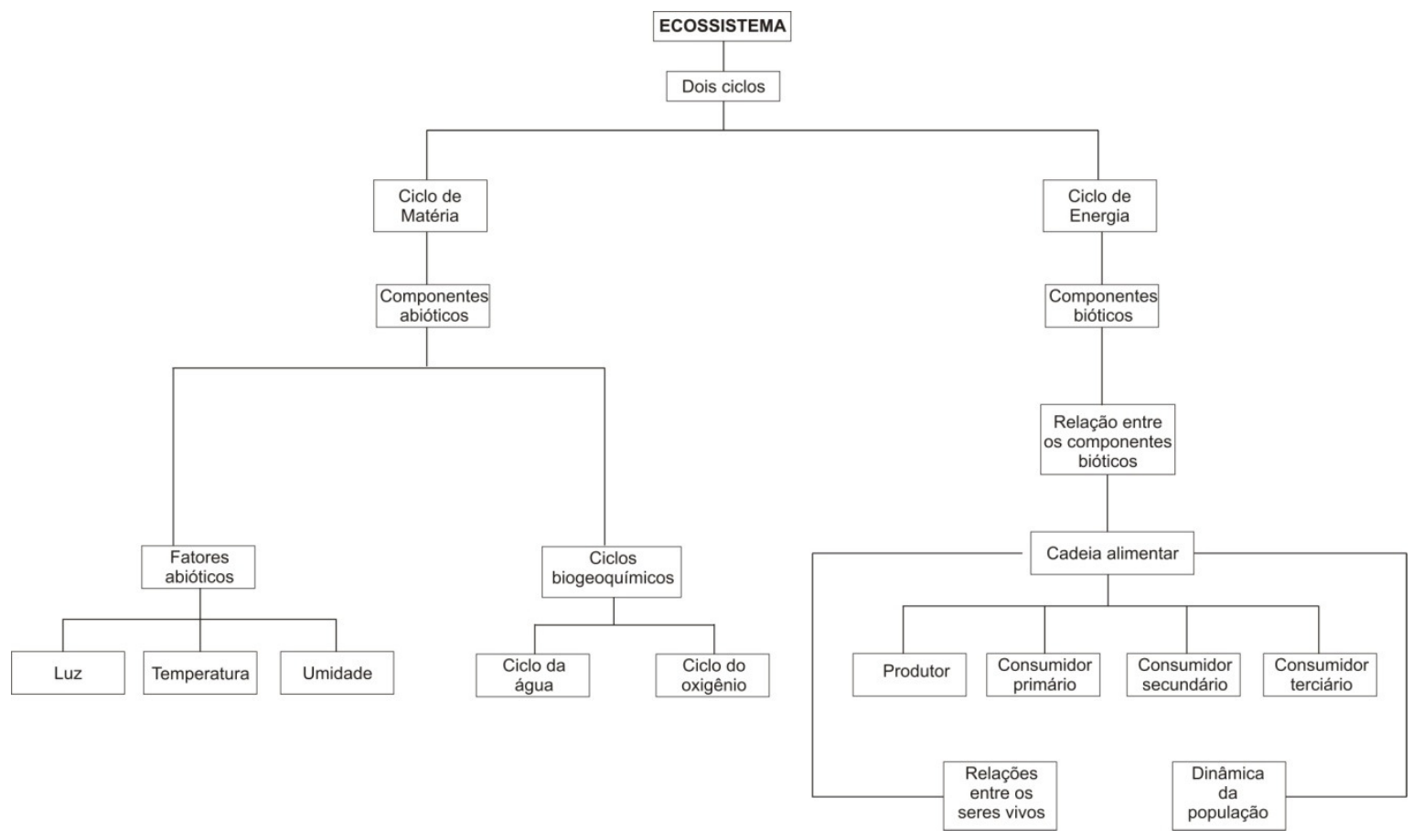

Figura 2 - Um mapa conceitual referente a teoria dos Ecossistemas (ROSA, 1996)

\section{Resultados e discussão}

A formação contínua constitui a articulação entre o trabalho docente, o conhecimento e o desenvolvimento profissional do professor, como possibilidade de postura reflexiva dinamizada pela práxis (LIMA apud ATENFELDER, 2004). Reforça-se, assim, a posição de Selles (2002), que considera imprescindível que o professor em exercício disponha de um programa de formação continuada, que funcione não apenas como oportunidade de atualização de conhecimentos, mas também como elemento "decodificador" das práticas vivenciadas no dia-a-dia em sala de aula.

Considera-se que as professoras que faziam parte deste GT estavam em exercício e a tarefa de produzir os planejamentos não deveria ser algo estranho à sua atividade profissional, porque o mesmo estava inserido no seu cotidiano pedagógico. Estes planejamentos deveriam, em tese, dar conta de todas as formas de interação, em classe, principalmente do conteúdo a ser ensinado via Terrário. O planejamento didático representa, implicitamente, um instrumento que fornece vários indicadores, entre os quais a forma de conceber o ensino de um dado conteúdo, sendo passível de crítica e contínua reelaboração (VILLANI, 1991; PACCA \& VILLANI, 1992, 1997; FREITAS \& VILLANI, 2002; BAROLLI, VALADARES e VILLANI, 2007). O planejamento também é considerado um instrumento de atualização constante, contribuindo para o crescimento intelectual do professor e o aumento da eficiência das atividades didáticas. 
No início, a pesquisa estava direcionada para acompanhar a prática pedagógica das professoras do GT 6a série. Esta questão sofreu um desvio de rota no decorrer do acompanhamento, porque no momento da utilização do Terrário para explorar questões relativas à Zoologia e/ou Ecologia, as professoras apresentaram muitas frustrações e dúvidas em relação ao uso do mesmo como estratégia didática para ensinar esses conteúdos. Essas dúvidas foram se tornando cada vez mais fortes no decorrer dos encontros do GT com a pesquisadora, tendo seu ápice na avaliação final dos planejamentos, através dos resultados desanimadores obtidos por cada uma das professoras durante a aplicação dos mesmos, envolvendo os Terrários.

As colocações das professoras do GT 6a série sobre os seus planejamentos neste momento foram uma clara demonstração das frustrações geradas dentro do grupo, as quais são exemplificadas pelos extratos de falas dos seus relatos:

Professora A: "estudar grupos zoológicos, através do Terrário, não deu certo. Usei o Terrário tentando observar transformações dos girinos, que é conteúdo da 6a série, dentro da Zoologia."

Professora B: "quanto aos animais, eles morrem em poucos dias, o que inviabilizou o trabalho de zoologia. Acredito que o estudo ficou em nível de cadeia alimentar."

Professora C: “...eu também, juntamente com os alunos, não tinha explicações, porque todos os animais do Terrário morreram".

Professora E: “....quanto à Zoologia, não deu para estudar bem ...”

As professoras, em geral, apontaram as seguintes questões que geraram incertezas no momento da utilização didática dos Terrários:

- opiniões divergentes quanto à série do ensino fundamental mais adequada para usar o Terrário como recurso;

- outro aspecto a ser salientado está relacionado com a questão do ar (o Terrário vedado por um plástico ou tampa), pois tanto crianças quanto adultos apresentam a concepção (MÁS,1996) de que a vida precisa de ar. Animais fechados numa caixa de vidro dão a impressão de que o ar vai faltar e tudo vai morrer, lembrando o fato quando do enterro de uma pessoa num caixão fechado. É a reação instintiva e correta que se traz incutida a respeito de que a vida só se mantém enquanto se está em contato com o ar. As professoras relataram, inclusive, que os seus alunos, por conta, começaram a fazer pequenos furos no plástico que tapava os Terrários, para que os animais não morressem; 
- dificuldade de imitar o ambiente externo em uma área restrita; na maioria das montagens sugeridas para o Terrário, não fica muito claro, em nenhum momento, ou não foi especificado, qual o ambiente será replicado, se é um jardim, um campo ou qualquer outro Ecossistema terrestre;

- impossibilidade de ensinar tópicos relacionados e/ou ênfase à Zoologia;

- a compreensão do ciclo da água via Terrário não ficou suficientemente esclarecida;

- em relação aos animais, nenhuma das leituras realizadas pelo grupo trazia recomendações quanto à coleta e o tipo de animal colocado no Terrário, pois o único prérequisito era ser pequeno. Houve várias colocações dos alunos que ficaram sem esclarecimentos por parte das professoras e cita-se como exemplo alguns extratos de falas mencionados pelas mesmas no âmbito da apresentação final do GT:

Professora C: ".... os alunos, diante da morte de quase todos os animais, observaram uma lesma que havia sido colocada no Terrário grudou-se na sua parede e não saiu mais... Aí meus alunos disseram: quem sabe ela não determinou a morte de todos " ?

Professora D: “...após 23 dias, quando fomos abrir para contar os animais, achamos a rã, que era enorme, pequena e magrinha, mas tão magra que as crianças acharam que era outro animal. Ela estava pele e osso. As crianças perguntaram: - será que não é um filhote? E os alunos também afirmaram: - faltou comida professora! Nossa, em vez de um Terrário montamos um Spa “!

A seguir, a partir dos relatos apresentados, verificou-se alguns conceitos da Teoria dos Ecossistemas que são violados na construção dos Terrários:

a) desconsideração ao habitat das espécies, uma vez que o professor e alunos coletam animais e vegetais de vários lugares para serem colocados no Terrário. Cita-se. por exemplo, na técnica de montagem proposta por Costa \& Nascimento (1994): "fazer um laguinho e colocar pequenos animais, como tatuzinhos de jardim, lagartas e alguns vegetais"; Maldaner \& Araújo (1989): "a recomendação é a de que se deve regar o solo, deixando-o bem úmido,sem encharcálo... como sugestão deve ser utilizado solo humoso, pequenos animais e água; quanto à idéia de Delizoicov \& Angotti (1994): "os animais colocados são minhocas e tatuzinhos do jardim"; Santana sugere (1992): "...é aconselhado que se regue a terra e coloque animais de pequeno porte". 
b) desrespeito em relação aos mecanismos de controle dos Ecossistemas que seriam os subsistemas microbianos, de comportamento e a relação predador-presa, que regulam a densidade populacional;

c) o comportamento dos animais (por exemplo, aranhas, minhocas, lesmas, caracóis e tatuzinhos de jardim) modifica-se completamente quando retirado do seu meio natural, ainda mais quando prisioneiro numa caixa de vidro ou pote fechado. Portanto, há um desrespeito ao seu nicho ecológico;

d) conceitos relacionados com cadeia alimentar, relações entre os seres vivos e dinâmica de populações são enfocados de uma forma incorreta. São colocados animais como aranhas e tatuzinhos de jardim que, na realidade, não estão localizados corretamente nos seus níveis tróficos. A mortalidade dos animais ocorrerá em pouco tempo, após serem colocados no Terrário, ficando extremamente complicada a análise dos conceitos acima mencionados, pois é uma população forjada, isto é, artificialmente montada e de maneira aleatória pois, conforme orienta Santana (1993): "que se coloque animais de pequeno porte como: formigas, aranhas, moscas, caracóis, tatuzinhos do jardim, etc...". São sugeridos também locais onde possam ser encontrados como no mato, jardins ou terrenos baldios.

As formigas vivem em colônias e são herbívoras, enquanto que aranhas alimentam-se de insetos, sendo de vida livre e solitárias. Em cativeiro podem jejuar e seus predadores são principalmente pássaros e lagartos. As minhocas vivem em solos ricos em húmus e úmidos, escondem-se em buracos, durante o dia, evitando o excesso de luz. Quanto às moscas, dependendo da espécie, umas são hematófagas e outras alimentam-se de frutas. Caramujos e lesmas são mais ativos à noite e, com o tempo úmido, alimentam-se de vegetais; durante o dia escondem-se embaixo de objetos, no solo, fendas ou buracos. E a morte deles vai se dar quase sempre devido à impossibilidade de se reproduzir, dentro do Terrário, as condições mínimas de sobrevivência.

Dentro da estrutura da teoria sobre cadeia alimentar proposta por Odum (1988), os organismos que compõem o Ecossistema podem ser agrupados de acordo com o modo pelo qual se alimentam, ou segundo o modo pelo qual obtém energia. Os decompositores constituem uma classe especial de organismos, sendo representados por microorganismos (fungos e bactérias), os quais obtém energia decompondo a matéria orgânica contida nos restos de animais e vegetais. $\mathrm{E}$, na maioria dos textos analisados, os decompositores não são citados e, mesmo assim, eles estarão dentro do Terrário. Também em relação ao fator tempo, observa que a quantidade de energia fixada num certo espaço de tempo não é considerada; 
e) o Terrário é considerado um sistema fechado em toda a bibliografia citada neste artigo, que embasou os planos das professoras do GT 6a série e é uma afirmativa errônea porque uma característica fundamental do Ecossistema é que ele é um sistema aberto, pois ocorrem interações com as vizinhanças, isto é, com todo o ambiente que o cerca. O termo sistema, empregado dentro da Ecologia, foi retirado da Física, mais especificadamente da Termodinâmica, no qual sistema é aquela parte do universo físico cujas propriedades estão sob investigação. Uma vez fixado, o sistema, tudo o que resta do universo, mas que tenha influência direta ou indireta no comportamento do mesmo, constitui o seu meio exterior. O sistema isolado não produz efeitos ou perturbações observáveis em suas vizinhanças. Dentro dos sistemas ecológicos não os teremos isolados, pois nenhum Ecossistema é fechado. Considerando os princípios da Termodinâmica, o Ecossistema é relativamente estável no tempo e aberto. Os sistemas ecológicos são sistemas abertos, com um ambiente de entrada e um de saída. Esta contribuição à conceituação de Ecossistema foi dada por Bertalanfly apud Odum (1988) através da Teoria geral dos Sistemas. E, em um sistema, existirá sempre uma entrada e uma saída de energia. Logo o Ecossistema é fechado para a matéria e aberto para a energia (luz).

Quando um sistema é pequeno, este depende em mais alto grau do exterior que um sistema de área maior. Somente os sistemas fechados à matéria como a biosfera podem funcionar sem outra influência externa que não seja a própria luz solar. Deste modo, justifica-se a importância de se considerar a influência dos fatores externos sobre os sistemas ecológicos.

f) é desrespeitada à 2a lei da Termodinâmica ou a Lei da Entropia (en = em, trope = transformação), que pode ser enunciada de várias formas, inclusive a seguinte: nenhum processo que implique numa transformação de energia ocorrerá espontaneamente, a menos que haja uma degradação da energia de uma forma mais concentrada para uma forma dispersa, pois o calor de uma chapa quente tenderá espontaneamente a se dispersar no ambiente mais frio. Ou, já que alguma energia sempre se dispersa em energia térmica não disponível, nenhuma transformação espontânea de energia (luz) em energia potencial (alimento) é $100 \%$ eficiente. Em relação à Entropia, Erwin Schrörindinger (1994), em seu livro, "O que é a vida" fez aportes essenciais da 2a lei da Termodinâmica com os organismos. Enquanto um organismo está vivo, alimenta-se de entropia negativa. O animal evita o declínio, isto é, sua morte, através do metabolismo (respiração) e o vegetal o faz pelo processo de assimilação (fotossíntese) logo, as plantas recebem o seu imprescindível fornecimento de entropia negativa da luz do sol;

g) os Ecossistemas e os organismos vivos são estruturas termodinâmicas abertas, que trocam matéria e energia com o ambiente, para diminuir a entropia interna, pois organismos em aquários e potes fechados não atingem esse status; 
h) somente uma parte muito pequena da energia luminosa absorvida pelas plantas verdes é transformada em energia potencial ou alimentar. A maior parte da energia vira calor, o qual logo passa para fora da planta, do Ecossistema e da biosfera; logo, o Ecossistema libera energia para o meio. A cada transferência de energia no Ecossistema há uma perda de calor, sendo que as transformações energéticas são em sentido único em contraste com o ciclo de materiais. Essa idéia é difícil de ser explicada com apenas alguns artrópodes, gramíneas, pequenas ervas, poucos animais e plantas confinados num recipiente de vidro ou similar, como acontece na montagem de um Terrário;

i) a presença de um organismo em um determinado local vai depender de um complexo de condições. Entre elas, as mais intimamente relacionadas com os animais terrestres são luz, temperatura e umidade, o que torna altamente complicado o controle em um Terrário.

j) a territorialidade, que é o modo como os indivíduos se distribuem no espaço, é mais pronunciada em artrópodes, que apresentam complexos padrões de comportamento reprodutivo, envolvendo construções de ninho, oviposição, cuidados e proteção da prole. E este é o grupo mais colocado no Terrário, por serem pequenos, como aranhas, formigas. larvas de borboleta, moscas e tatuzinho do jardim, não sendo respeitada a sua territorialidade e nicho ecológico.

I) o ciclo da água constitui um dos ciclos biogeoquímicos e o processo que vai ocorrer no Terrário é apenas uma condensação, não um ciclo de água semelhante ao que ocorre na natureza. A maioria dos autores analisados afirma ensinar o ciclo da água através do Terrário. Alguns inclusive enfatizam também o ciclo do oxigênio e gás carbônico via Terrário. Acrescenta-se como ilustração uma declaração feita pela professora C do GT 6 a série, no momento da apresentação final do mesmo, relacionado ao relato de um aluno sobre o ciclo da água: “...Professora eu observo que a água escorre pelas paredes do Terrário e caía água da tampa dele, mas eu não consigo enxergar as nuvens que provocam esta 'chuva' e nem o vento". Isto suscitou uma série de dúvidas, tanto para ela quanto para o aluno (MÁs, 1996). A professora E acrescentou: "os meus alunos só perceberam a evaporação e não o ciclo da água";

m) as interações entre os organismos não ocorrem dentro do Terrário. Estas relações associativas são complexas para serem representadas no mesmo. Os conceitos de população e comunidade são extremamente difíceis de serem trabalhados neste tipo de construção;

n) um dos animais que freqüenta com grande assiduidade os Terrários nas sugestões de montagem dos mesmos é o tatuzinho do jardim (nome científico: Armadillidium vulgare que pertence ao Reino: Animalia; Filo: Artropoda; Subfilo: Crustacea; Classe: Malacostraca; Ordem: 
Isopoda e Subordem Oniscidea). O que ele tem a seu favor, além do seu tamanho diminuto, é a facilidade de ser encontrado embaixo de tijolos que ficam à sombra, em lugares úmidos. Na realidade, é desnecessário, pois conhecemos muito pouco da sua Ecologia em nível de livro didático de Ciências. Além do mais, têm hábitos noturnos e ficam dentro do Terrário enrolados a maior parte do tempo, num movimento de defesa ou embaixo de pedras, que é o seu habitat natural. Eles tem hábitos herbívoros e se alimentam principalmente de excrementos de animais presentes no solo;

o) processos metabólicos complexos como fotossíntese e respiração ficam apenas na pretensão, pois não são visíveis em um Terrário. Como exemplo, evocamos a frase da professora E, sobre o processo fotossintético (BARRABín \& SÁNCHEZ, 1996): "a observação da fotossíntese fica em nível de verde, sua presença lembra oxigênio, logo, a fotossíntese vem do verde“;

p) outra questão importante é o comportamento dos animais. A grande maioria dos animais como as lesmas, caracóis, tatuzinhos do jardim, minhocas colocados no Terrário possui hábitos noturnos e as aulas são diurnas, ficando prejudicada qualquer tentativa de observar a sua Etologia.

Ao se comparar o Terrário com o material que é usado em Ecologia experimental para representar um Ecossistema terrestre, os chamados microcosmos ou microecossistemas (ODUM, 1988), constata-se não haver pontos em comum com o Terrário. Os microcosmos são modelos (simplificações) vivos e funcionais da natureza, mas não devem ser considerados duplicatas do mundo real, apenas representações. E, na maioria das propostas de montagens sugeridas para o Terrário, segundo os autores citados no início desse artigo, que embasaram teoricamente os planos de aula das professoras do GT 6a série, isto não ficava muito claro, em nenhum momento, ou não era especificado qual o ambiente replicado. Ainda, deveríamos utilizar o termo "microecossistema" ao invés de "Ecossistema", levando em conta a sua escala de representação.

Outro resultado auferido é que, na maioria das vezes, o aluno é incentivado a atuar como um pequeno pesquisador, fortalecendo o "mito do cientista". As tentativas de respostas dadas, em relação aos conceitos ecológicos, via Terrário, não funcionam, assim como não possibilitam uma consciência ecológica, uma vez que os próprios conceitos da teoria não são respeitados. A Ciência trabalha com modelos. Porém, ao considerarmos que os modelos devem ser o mais idênticos possíveis ao real, o Terrário, enquanto modelo de Ecossistema terrestre, não serve como tal.

Os professores estão sempre à procura de sugestões didáticas que Ihes facilitem a vida escolar e o Terrário se enquadra enquanto guia de procedimentos. O mesmo tem, por parte da 
comunidade de professores de Ciências, uma grande aceitação, o que pôde ser exemplificado pelos registros que faremos logo abaixo. Há um número expressivo de publicações e relatos de experiências em congressos da área de ensino de Biologia, que incentivam a utilização do Terrário como recurso didático. Mas, nestas obras não temos o registro de investigação e/ou elucidação da teoria que esta por trás da montagem do Terrário. Também não se apresentam os registros dos resultados da aplicação desse guia de procedimento com os Terrários. Cita-se o artigo da revista Nova Escola, de abril de 1995, no qual os editores receberam inúmeras correspondências de professores de Ciências, que desejavam maiores informações sobre a montagem do Terrário idealizado por Colonesse (1994); além de Araujo \& Ferreira (2000), em uma comunicação oral apresentada no VIII EPEB (Encontro de Perspectivas e Ensino de Biologia), na USP (Universidade de São Paulo), São Paulo, sob o título "Concepções dos (as) graduandos (as) do curso de Ciências Plena/Habilitação Biologia e Química sobre o tema 'Ecossistema' e o modo de ensiná-lo no ensino fundamental"; no qual, segundo a pesquisa, 6,9\% dos entrevistados indicaram o Terrário. Também são encontradas sugestões nos guias didáticos, habitualmente utilizados no ensino fundamental, como Cruz (1999), Gewandsznadjer (2005), Gowdak \& Martins (2006). E, inclusive, no livro didático Bizzo \& Jordão (2005, p. 25), há uma sugestão de se observar o ciclo de Carbono através de uma garrafa plástica totalmente vedada, dentro da qual convivem pequenas plantas. Então, pode-se, após essa breve citação bibliográfica, constatar que o Terrário continua sendo, ainda, até os nossos dias, muito divulgado entre a comunidade de professores de Ciências Biológicas, pois o mesmo carece de uma análise mais criteriosa, que este artigo pretende propiciar, instigando a discussão e a reflexão de todos os colegas da área de Ciências, principalmente no tocante ao ensino de Ecologia.

O Terrário pareceu às professoras, inicialmente, um ótimo recurso, que auxiliaria os alunos a compreenderem melhor as aulas de Zoologia e as de Ecologia. Porém, com o transcurso dos trabalhos ficou evidente a decepção em relação aos objetivos traçados inicialmente, o que possibilitou, uma análise da validade ou não de se utilizar o Terrário como modelo de Ecossistema, ou melhor, Microecossistema Terrestre. Ao término das análises, concluiu-se que utilizar Terrários como modelo para facilitar a compreensão da Teoria dos Ecossistemas não é o melhor recurso para esse fim. Pelas inúmeras falhas apontadas, como a violação dos inúmeros princípios da Teoria Ecológica, entre eles, a falta de referências quanto à quantificação de água, terra, animais e vegetais, que devem ser colocados no Terrário. Portanto, não são respeitadas escalas e também não se identifica que tipo de microecossistema se estaria representando no Terrário. 


\section{Conclusões}

Evidenciou-se, através desse trabalho, as inúmeras dificuldades enfrentadas no acompanhamento dos professores em sua prática, através da perspectiva da formação continuada, evidenciando a necessidade de maiores debates e planejamentos das tarefas propostas. Porém, apesar de tantas barreiras, há vários pesquisadores da área como Bueno \& Cattani (1998), Alarcão (1998), Belintane (2002), Candau (2001), Geglio (2003), Perrenound (2002), Pimenta (2002), Selles (2002), Mizukami (2002), entre outros, que apostam nesta perspectiva para tentar reverter o quadro atual do profissional da educação.

Pode-se concluir, através deste trabalho, que o Terrário, nas aulas de Ecologia, é um recurso questionável, pois não serve nem como modelo nem como ilustração de Ecossistema terrestre.

Finalmente, fica a sugestão de que, para estudar temáticas relacionadas aos microecossistemas terrestres, substitua-se o Terrário por uma área delimitada, que pode estar situada em um campo, pomar, um pequeno jardim, o pátio da escola ou uma situação ambiental qualquer, próxima à comunidade escolar, como por exemplo, uma microbacia (ex: arroio ou outro manancial de água). Sugere-se, ainda, situações bem pontuais, identificadas no próprio cotidiano da escola, como a coleta de lixo, destino dos papéis, latas, pilhas, óleos utilizados na cozinha da escola, lâmpadas ou ainda qualidade e controle do gasto da água e da energia elétrica na escola.

\section{Bibliografia}

ALARCÃO, Isabel. Formação Continuada como instrumento de profissionalização docente In: VEIGA, IIma Passo A. (org.). Caminhos da profissionalização do magistério. Campinas: Papirus, 1998.

ALTENFELDER, Anna Helena. Formação continuada: os sentidos atribuídos na voz do professor. Dissertação de Mestrado. São Paulo: PUCSP, 2004.

ARAÚJO, Maria Cristina Pansera (org.). Animais no meio ambiente: integração e interação.

Coleção Ensino de 1o grau Séries textos didáticos. ljuí: UNIJUÍ, 1989.

ARAÚJO, Maria Cristina Pansera \& FERREIRA, Francesca Werner. Concepções dos graduandos do curso de Ciências Plena - Hab. Biologia e Química sobre o tema Ecossistemas e o modo de ensinálo no fundamental. Comunicação apresentada em 22/06/2000, no VI EPEB - Encontro de

Perspectivas do Ensino de Biologia, Universidade de São Paulo, USP, 2000.

ARMANDO, Márcio \& ARAÚJO, Maria Cristina Pansera de. Práticas de biologia para uma ciência viva. Ijuí: UNIJUI, 1988. 
BAROLLI, Elisabeth; VALADARES, Juarez M. \& VILLANI, Alberto. Explicitando uma metodologia de pesquisa: a experiência de uma professora de Física revisitada. Ciência \& Educação, Bauru, vol. 13, n. 2, pp. 253- 271, 2007.

BARRABÍN, Jordi de Manuel; SÁNCHEZ, Ramon Grau. Concepciones y Dificultades comunes em la construcción del pensamiento biológico. Alambique, Didáctica de las Ciencias Experimentales, ano III, n. 7, Barcelona: Enero, 1996.

BELINTANE, Claudemir. Por uma ambiência de formação contínua de professores. Cadernos de Pesquisa, São Paulo, FACED, USP, n. 117, pp.177-193, nov.2002.

BIZZO, Nélio \& JORDÃO, Marcelo. Ciências BJ 6ạ série. São Paulo: Editora do Brasil, 2005.

BUENO, Belmira de Oliveira. Pesquisa em colaboração na formação contínua de professores, In: Bueno, Belmira Oliveira; CATANI, Denice Bárbara; SOUZA, Cynthia Pereira (Orgs.). A vida e o ofício dos professores. São Paulo: Escrituras, 1998.

BUENO, Rogério M. (org.) Ensino de ciências: projetos alternativos (adequados para 5a ou 6a séries do 1ạ grau. 2. ed. ljuí: UNIJUI, 1989.

CANDAU, Vera Maria. Universidade e formação de professores: Que rumos tomar ? In: CANDAU, Vera Maria (Org.). Magistério: construção cotidiana. Petropólis: Vozes, 2001.

COLONESE, Paulo Henrique. Ecossistema engarrafado. Nova Escola, São Paulo, ano IX, n. 81, pp.18-19, dez. 1994.

COSTA, Marilene A. Silva da \& NASCIMENTO, Silvana Sousa do. Previsões e observações de um terrário: uma experiência coletiva. Comunicação apresentada em 28/07 /1994, no V EPEB, Encontro de Perspectivas do Ensino de Biologia, Universidade de São Paulo, USP, 1994.

CRUZ, Daniel. Ciências: educação ambiental - os seres vivos. 24. ed. São Paulo: Ática, 1999. DELIZOICOV, Demétrio \& ANGOTTI, José André. Metodologia do ensino de ciências. 2. ed. São Paulo: Cortez, 1994.

ESPAÇO CIÊNCIA VIVA. Terrário. Apostila do espaço Ciência Viva (ECV). Museu Participativo de Ciências do Rio de Janeiro, 12 p, mimeo. 1994.

FREITAS, Denise de; VILLANI, Alberto. Análise de uma experiência didática na formação de professor de Ciências. Investigações em Ensino de Ciências, Porto Alegre, v.7, n. 3, pp.25-37, 2002.

GEGLIO, Paulo César. Formação continuada de professores e mudança de prática: uma análise a partir da narrativa de professores. Tese de Doutorado. São Paulo: Programa de Psicologia da Educação, PUCSP, 2003. 
GEWANDZNADJER, Fernando. Ciências: 5a Série - o planeta Terra. 2. ed. São Paulo: Ática, 2005. GOWDAK, Demétrio \& MARTINS, Eduardo. Seres vivos - 6ạ série. São Paulo: FTD, 2006.

LAWSON, A. E. Uso de ciclos de aprendizaje para la enseñanza de destrezas de razonamiento científico y de sistemas conceptuales. Enseñanza de las Ciencias, Barcelona, v. 12, n.2, pp.165187, 1994.

MALDANER, Otávio Aloísio \& ARAÚJO, Maria Cristina P. A formação continuada do professor e a mudança da sala de aula: A participação do professor na construção do currículo escolar em Ciências. Espaços da Escola, ljui, Livraria Editora da UNIJUÍ, ano I, n 3, pp.18-28, jan./mar. 1992.

MÁS, Carles J. Furió. Las concepciones alternativas del alumnado en Ciencias: dos décadas de investigación. Resultados y tendências Alambique Didáctica de las Ciencias Experimentales, ano III, n. 7, Barcelona, enero, 1996.

MIZUKAMI, Maria da Graça N. et al. Escola e aprendizagem de docência: processos de investigação e formação. São Carlos: Ed. UFSCAR, 2002.

ODUM, Eugene P. Ecologia. Rio de Janeiro: Guanabara Koogan, 1988.

PACCA, Jesuína L. A.; VILLANI, Alberto. Estratégias de ensino e mudança conceitual na atualização de professores. Revista Brasileira de Ensino de Física, São Paulo, v .14, n. 4, pp. 222-228, 1992.

PERRENOUND, P. A prática reflexiva no ofício de professor: profissionalização e razão pedagógica. Porto Alegre: Artmed, 2002.

PIMENTA, Selma Garrido. Professor reflexivo construindo uma crítica. In: PIMENTA, Selma Garrido ; GHEDIN, Evandro (Orgs.) . Professor reflexivo no Brasil: gênese e crítica de um conceito. São Paulo: Cortez, 2002.

ROSA, Rosane Teresinha Nascimento da. Terrários no ensino de ecossistemas terrestres: modelo ou ilustração? Dissertação de Mestrado. Santa Maria: Universidade Federal de Santa Maria, UFSM/CE, 1996.

SANTANA, Margarida Carvalho de. Crianças fazem uma viagem ao planeta Terra. Revista do Professor, Porto Alegre, 8 (32), out./dez. 1992

. O mundo em que vivemos - Ciências - 4. Rio de Janeiro. Governo de Estado do Rio de Janeiro - Secretaria Extraordinária de Programas Especiais-- Fundação de Apoio à Escola Pública (FAEP), 1993

SELLES, Sandra Escovedo. Formação continuada e desenvolvimento profissional de professores de Ciências: Anotações de um projeto. Ensaio - Pesquisa em Educação em Ciências, Faculdade de Educação / Espaço UFF de Ciências, Universidade Federal Fluminense, vol.2, n.2, dez. 2002. 
SHÖRINDINGER, Erwin. $O$ que é vida? 2. ed. São Paulo: Fragmentos, 1994.

VILLANI, Alberto. Planejamento escolar: um instrumento de atualização dos professores de Ciências. Revista do Ensino de Física, v. 13 p. 162 - 177,dez, 1991

VILLANI, Alberto; PACCA, Jesuína Lopes de Almeida . Construtivismo, conhecimento científico e habilidade didática no ensino de ciências. Revista da Faculdade de Educação da USP, São Paulo, v. 23, n.1-2, pp. 196-214, 1997.

Rosane Teresinha Nascimento da Rosa. Doutoranda do Programa de Pós-Graduação Educação em Ciências: Química da Vida e Saúde - UFSM/RS. 